\title{
Integrating Knowledge with Suppliers at the R\&D-Manufacturing Interface
}

\author{
David T. Rosell, \\ Department of Management and Engineering, Linköping University, Sweden, \\ Nicolette Lakemond, \\ Department of Management and Engineering, Linköping University, Sweden, \\ and \\ S. Nazli Wasti \\ Department of Business Administration, Middle East Technical University, \\ Turkey
}

\begin{abstract}
Purpose - Many manufacturing firms source components and subsystems from suppliers. Consequently, the suppliers' product and manufacturing knowledge is a central concern at the interface between R\&D and manufacturing. This paper specifically investigates how supplier knowledge is integrated and what role trust plays in knowledge integration with suppliers at the $R \& D$ - manufacturing interface.

Design/methodology/approach - The study is based on qualitative case studies of two different collaborations with suppliers at one firm.

Findings - Two distinct processes are identified. First, capturing represents knowledge integration through decoupling, for which a basic level of trust specifically with regard to the competence of the supplier is necessary. Capturing can take place through interactions that are limited in time and scope. Second, joint learning represents a coupled knowledge integration process and takes place during a more extended period of time preceding and following the R\&D-manufacturing interface and builds on relational-based trust.

Practical implications - The interface between $R \& D$ and manufacturing needs to be extended to include a focus on suppliers' contributions in terms of product and manufacturing knowledge. The choice for suitable knowledge integration processes needs to be guided by concerns about the level of trust and the character of the supplier contributions. Originality/value - The paper adds new insights to previous literature by distinguishing between different types of knowledge integration processes and levels of trust. It bridges the gap between innovation and operations management, and clearly shows that the interface between $R \& D$ and manufacturing crosses organizational borders.
\end{abstract}

Key words Knowledge integration; Buyer-Supplier collaboration; Trust; Product development; R\&D-manufacturing interface 


\section{Introduction}

Suppliers are increasingly contributing to their buyer's product development processes and acting as production partners (e.g., Appleyard, 2003, Beecham and Cordey-Hayes, 1998, Lau et al., 2010). In a recent report on global manufacturing by KPMG (KPMG, 2012), it is emphasized that tighter collaboration with suppliers is an important trend in the manufacturing industry, not only for manufacturing and logistics, but also specifically with regard to R\&D activities. Consequently, the interface between $R \& D$ and manufacturing does not only involve internal functions, but includes external supplier relationships. These supplier relationships represent an important source of knowledge that has to cross the R\&D manufacturing interface in order to be integrated. Trust appears to be an important antecedent in these relationships as it increases the likelihood that information is being shared between the organizations (e.g. Ha et al., 2009; Fawcett et al., 2012, Lincoln et al., 1998; Squire et al., 2009, Walter, 2003). Consequently, while there is a fair amount of literature on work integration at the R\&D-manufacturing interface, the knowledge relationships and knowledge integration processes between buyers and suppliers at this interface have received less attention (Hong et al., 2004; Nobelius, 2004).

Increased levels of knowledge integration between buyers and suppliers can help improve products and processes, decision making, and the problem resolution of product development and manufacturing by taking advantage of suppliers' product technology and manufacturing expertise (Appleyard, 2003; Bentson et al., 2013; Cousins et al., 2011; Ragatz et al., 2002). A supplier can take responsibility for product engineering activities as well as provide input to align the supplier's manufacturing process to the buyer's design (Rosell and Lakemond, 2012; Koufteros et al., 2005). Supplier knowledge about a specific product technology tends to extend the $R \& D$-manufacturing interface to the product design phase of the product development process, the technology is often risky, not always completely understood, and may require refinement before it can be integrated by the buyer firm (Tatikonda and Stock, 2003). Consequently, knowledge integration in these buyer-supplier collaborations often relies on exploration, which is characterized by a high degree of risk-taking, search and experimentation (cf. March, 1991). Buyer-supplier collaborations that focus on supplier knowledge about process technologies and improvements are usually based on an impetus on the part of the supplier about alternatives related to material specifications, material availability, material cost, and scheduling (Koufteros et al., 2005). This knowledge about process technologies tends to be rather well specified and less uncertain in nature (Tatikonda and Stock, 2003), i.e. it relies to a higher degree on exploitation (cf. March, 1991). It is reasonable to expect that these different characteristics influence how supplier knowledge is integrated in new product development (Rosell and Lakemond, 2012). However, there is little empirical evidence demonstrating how these product and process technology knowledge integration processes in buyer-supplier collaborations enfold at the $\mathrm{R} \& \mathrm{D}$ - manufacturing interface. Therefore, by taking into consideration different types of collaborations, this paper investigates how supplier knowledge is integrated in product development collaborations. Two main research questions guide our research: What characterizes the knowledge integration processes in buyer-supplier collaborations in product development? What is the role of trust in these processes? The second research question is investigated because trust can take different forms and may provide different prerequisites in buyer-supplier collaborations in different situations (cf. Blomqvist, 1997; Sengün, 2010).

The paper is structured as follows: First a theoretical framework related to the subject of knowledge integration and trust in product development collaborations is provided. Then, the methodology chosen for the study is presented. The paper proceeds with a presentation of the findings which is followed by an analysis of the data. Finally, there is a conclusion where managerial implications and suggestions for further research are presented. 


\section{Theoretical framework}

\subsection{Knowledge integration in product development}

Product development processes can be described as the exchange and utilization of information and knowledge, like a communication web (Brown and Eisenhardt, 1995). In a similar way, product development has been characterized as a process in which the sharing, creation and application of knowledge is central (Huang and Newell, 2003; Nonaka 1994; Nonaka and Takeuchi, 1995; Alawi and Tiwana, 2002). The result of this process is embodied in a new product with accompanying production processes which indicates the importance of the R\&D-manufacturing interface. It is not likely that all the necessary knowledge resides in one single firm. Consequently, knowledge is a resource that often needs to be integrated through external collaborations (Dyer and Singh, 1998; Grant and Baden-Fuller, 2004).

In the knowledge based view of the firm, the integration of knowledge is the key to the competitiveness and the survival of the firm (Grant, 1996; Kogut and Zander, 1992). The knowledge based view of the firm focuses particularly on the efficiency of integration which is related to the efforts made by the firm to integrate specialist knowledge. Grant (1996) focuses on communication mechanisms the integration of knowledge, and proposes four mechanisms: rules and directives, routines, sequencing and group problem-solving. The first three focus on minimizing communication while only the latter, 'group problem-solving and decision making' is a communication-intensive form of integration, relying upon high interaction. It has been argued that reliance on this mechanism tends to increase when task complexity is high (Grant, 2002; Van de Ven et al., 1976).

The efficiency perspective on knowledge integration might not fully reflect the complexity of knowledge integration between buyers and suppliers at the R\&D-manufacturing interface. Koufteros et al. (2005, p. 102) discuss this as follows: "On the surface, it may look like suppliers are given basic functional specifications and are asked to complete all technical specifications and sometimes to include materials to be used. The likelihood is that this is more complicated, and indicative of a more intimate relationship between a supplier and a customer. The supplier is expected to have a sixth sense, reading what the customer has in mind. The supplier has to have a picture of expectations and the supplier has to connect with this picture. However, this picture is often latent and represents an amalgam of views produced by various constituents". This can be further explained by considering the characteristics of knowledge. Knowledge can be understood as explicit, knowing what, or tacit, knowing how (cf. Nonaka, 1994; Polanyi, 1966). Many researchers have emphasized the importance and the challenge of managing knowledge in organizations and particularly tacit knowledge (e.g. Kogut and Zander, 1992; Nonaka 1994; Polanyi, 1966). The challenges are related to the fact that knowledge normally resides within individuals and that individuals normally know more than they can tell, as Polanyi (1966) would have put it. In product development, individuals in different organizational functions have know-how that is not easily transmitted across boundaries (cf. Carlile, 2002). It is not just about finding a syntax to share knowledge, but it is also a semantic challenge to utilize specialist knowledge and to cocreate new knowledge. Thus, cognitive limitations (Carlile, 2002), and especially in interorganizational settings also the risk of opportunism, make knowledge difficult to manage (cf. Heiman and Nickerson, 2002, 2004).

While Grant's (1996) and Schmickl and Kieser's (2008) approaches focus on efficient mechanisms and impersonal interfaces, Okhuysen and Eisenhardt (2002) have a different focus when they describe knowledge integration as a learning process, where individuals collaborate, share, and combine specialised knowledge to generate new knowledge. The focus on interactive processes is also acknowledged by Tiwana and McLean (2005), who argue that 
the integration of knowledge differs from the sharing and transfer of knowledge. Knowledge integration involves and builds on sharing, but goes beyond it (Okhuysen and Eisenhardt, 2002). It also involves a combination and a generation of new knowledge. Henderson and Clark (1990) use the terms extension and reconfiguration of knowledge to describe this process. Extension captures an innovation's impact on components, while reconfiguration captures its impact on the linkages between components. On a product component level this is reflected in the extending of existing capabilities with additional knowledge, and on the architectural level, the existing knowledge is reconfigured into new types of capabilities. However, although it may be possible to make a conceptual distinction between combining, extending and reconfiguring, these processes are heavily intertwined in practice. Here, we want to make the point that knowledge integration embraces not only knowledge sharing, but also a process of using the knowledge that is shared. Thus, knowledge integration is not simply a matter of assembling discrete pieces of knowledge, like Lego blocks, as the "knowledge as a resource" view implies. Instead knowledge integration depends on how individuals know and integrate their specific knowledge, and where the outcome "consists of both the shared knowledge of individuals and the combined knowledge that emerges from their interaction" (Okhuysen and Eisenhardt, 2002: 384). This process leads to the creation and application of new knowledge which is finally embodied in a new product (Alawi and Tiwana, 2002; Nonaka: 1994, Nonaka and Takeuchi, 1995) Thus, in this study knowledge integration is defined as a process that starts by the sharing of knowledge, but also involves utilization, i.e. a combination of knowledge, which extends and/or reconfigures knowledge, in order to generate and apply new knowledge.

Several antecedents for knowledge integration can be found in the literature. These include factors such as the heterogeneity of expertise, the quality of the relationships, the ability to interrelate with peers outside their own domain (Tiwana and McLean, 2005), past experience of collaboration, adequate organizational structures (Huang and Newell, 2003), communication, and deep and connected relationships (Hammerwoll, 2012). Consequently, it is seems that knowledge integration is not just about cognition and coordination but also about cooperation and trust (Grandori, 2001; Grant, 2002).

\subsection{Trust}

Ever since Japanese supplier relationships became the role model for successful supplier involvement in product development (Clark, 1989), trust has been considered to be an important success factor for buyer-supplier relationships. Japanese supplier relationships rely to a high degree of trust and are characterized by the mutual investments of the supplier and buyer, the establishment of clear norms, and the creation of a reputation (Smitka, 1991). The importance of trust has also been confirmed outside the Japanese context (Dyer and Chu, 2003; LaBahn and Krapfel, 2000; Ragatz et al., 1997; Sako and Helper; 1998; Walter, 2003).

Trust has been defined in different ways such as confidence in another's goodwill (Ring and Van de Ven, 1992) or as the subjective probability with which an actor assesses that another actor will perform a particular action, both before the primary actor can monitor such an action and in a context in which it affects her or his actions (Gambetta, 1988). Trust has been shown to lead to greater knowledge sharing (Nahapiet and Ghoshal, 1998; Tsai and Ghoshal, 1998; Dyer and Nobeoka, 2000; Adler and Kwon, 2002; Inkpen and Tsang, 2005) and has been found to be a critical factor in inter-organizational learning (Hansen, 1999). Trust facilitates information sharing and learning because it creates a belief between parties that information sharing increases not only the size of the pie but also their share of the pie (Selnes and Sallis, 2003).

Even though there are many studies that confirm that trust has a positive impact on knowledge integration (Ha et al., 2009; Lincoln et al., 1998; Squire et al., 2009), few have 
considered the situational aspect of trust and its consequences for knowledge integration in buyer-supplier collaborations at the R\&D-manufacturing interface. There are, however, some indications that the role of trust in product development collaborations is contingent upon the specific situation (Bhandar et al., 2006). Different dimensions of trust have been identified; trust related to familiarity and repeated interaction, trust related to norms that create predictability and trustworthiness, and a calculative form of trust related to (self-) interest and an assessement of costs and benefits of a potential exploitation of vulnerabilities (Adler, 2001). In this paper we distinguish between competence-based trust which is based on technical capabilities, skills and know-how, and relational trust which is based on goodwill and moral responsibility towards one another (cf. Adler, 2001; Blomqvist, 1997; Nooteboom, 2003; Sako, 1992; Sengün, 2010). For example, Sako (1992; p. 36-39) defines competence trust as the expectation that the other party will perform its role competently; i.e., the belief that the other party has the technical and managerial competence to complete what it is promising to do. Sako (1992) defines goodwill trust as the willingness of the other party to do more than is formally expected. Here the other party is expected to be dependable and be trusted to refrain from unfair advantage taking, even though there may be no explicit promises to be fulfilled. A basic distinction between the two trust types concerns the sort of information needed to grant trust. While it is possible to screen for competent behavior by referring to market reputation, relational trust is more contextual and particularistic and is verifiable only through mutual engagement.

According to Sengün (2010), relational trust increases the chances of effective interorganizational learning by delivering a higher level of involvement and open commitment by the knowledge seeker and a reduction of the risk of exploitation. While Luo (2006) expects competence trust to facilitate both the extent and the efficiency of inter-organizational learning by allowing the recipient to recognize and value the new knowledge provided by another party, Sengün (2010) argues that the role of trust based on competence trust on interfirm learning will be quite different, as competence trust does not have anything to do with the open commitment, extended effort, and involvement necessary for effective learning. Her results suggest a positive and significant correlation between relational trust and inter-firm learning, while no association was found between competence-based trust and inter-firm learning. This indicates that trust per se is no guarantee for fostering inter-firm learning, but that it is the type of trust that matters. Consequently, a further investigation of the role of trust for knowledge integration in different buyer-supplier collaborations is necessary. This may have implications for buyer-supplier collaborations focused on product technology, which tend to rely on uncertain and exploratory processes, and collaborations focused on manufacturing processes which represent more specified collaborations (Tatikonda and Stock, 2003).

\section{Methodology}

\subsection{Research design}

Since the aim of our research is to investigate knowledge integration in buyer-supplier collaborations at the R\&D-manufacturing interface, qualitative case studies at one firm were carried out. This is also what Yin (2009) considers as an appropriate research strategy to gain understanding of a phenomenon in its context.

We set out to find a firm that was not expected to have all knowledge necessary for product and process development residing within the company, i.e. a firm that relied on external collaborations with suppliers. The criteria for selecting such a firm included that the 
focal firm should be a high-tech manufacturing company that had a relatively high level of R\&D activity, relatively complex products consisting of a number of components and subcomponents, and that is was relatively experienced in collaborating with suppliers in R\&D.

An international first tier supplier in the automotive industry allowed us access to its supplier-collaborations. The automotive industry is well-known for involving suppliers in R\&D activities (e.g. Liker et al., 1996), and has been pointed out that knowledge integration in buyer-supplier relationships is an important challenge in this industry (Becker et al., 2003). At this firm, referred to as CARCOM, a project aimed at developing a new generation discbreak was selected. This paper is based on case studies of collaborations between this firm and two suppliers within this project. The two cases - the holder collaboration and the caliper collaboration - are different in character when it comes to the scope and depth of the collaboration. Thus, two unique NPD settings were established. The holder collaboration focused on developing a completely new design. The supplier of this component is mainly involved for its product technology knowledge. The caliper collaboration focuses on improving quality and decreasing cost. The involvement of the supplier is mainly for its knowledge about the components manufacturability. Consequently, the two cases represent different situations that are used for comparison and developing theoretical insights (Yin, 2009) of knowledge integration and trust at the R\&D-manufacturing interface.

\subsection{Data collection}

Data was collected through 12 interviews with key informants from the two collaborations; strategic purchasing staff, designers, and manufacturing engineers. We were also able to talk to representatives from the suppliers who provided additional valuable insights. By selecting individuals that had access to the collaboration and who had different roles and responsibilities in the project, the representativeness of the respondents' insights was ensured (Alvesson, 2011). In order to gather data that was as rich as possible, face-to-face semistructured interviews were conducted (Eisenhardt and Graebner, 2007). Each interview lasted on average one hour. The interviews were recorded and thereafter transcribed. In addition to the interviews, complementary data was gathered by studying project documents. By systematically documenting the interviews and asking the companies for feedback on drafts of the case reports, data analysis was made possible and practical relevance and validity strengthened (Miles and Huberman, 1994).

To make the study consistent and reliable, an interview guide was used for the thematic questions and the software NVivo for the systematic documentation. This is also in line with what Yin (2009) suggests about setting up a detailed case study protocol and a database.

\subsection{Data analysis}

As Yin (2009) suggests, case study analysis requires a case description by the researcher. Therefore, before the actual analysis, an elaborated case description of each collaboration was narrated. These descriptions include data from the interviews as well as data collected from relevant documents. The analysis itself was essentially performed by classifying the narratives into content categories in order to structure the data (Miles and Huberman, 1994). This was not a strict inductive approach to reach theoretical saturation (cf. Eisenhardt, 1989), but an abductive one (Yin, 2009). Starting with a general theoretical framework with general themes, new codes where added and deleted when working with the empirical material. The aim was to understand the role of trust for knowledge integration. Cases with different characters were 
used to improve theoretical insights and allowed us to contrast collaborations of different scope and depth, i.e., collaborations focused on product technology and exploration versus collaborations focused on manufacturing process technology and exploitation.

To ensure internal validity, pattern matching was used by comparing the empirical patterns with the predicted. It was predicted that knowledge integration processes and trust would be different in the different types of collaborations. In the cases studied, coinciding patterns, within and between the two types of trust identified in the theoretical framework strengthened internal validity. Thus, there was a match between the observations and the ideas that were developed (Bryman, 2008). In order to determine if the findings were accurate from the interviewees' perspectives, the results were validated by checking with the companies (cf. Creswell, 2009). The idea was not to generalize the findings to a population but to theory (Yin, 2009). Although the empirical data was drawn from only two cases, it was possible to carry out analytical generalization (Firestone, 1993). Yin (2009) argues that this form of generalization occurs when the researcher studies additional cases and generalizes the findings to theory. By using cases that represent two extremes of collaboration, we could improve the theoretical insights of the knowledge integration and trust between the buyer and its suppliers in relation to the R\&D-manufacturing interface.

\section{Empirical findings}

\subsection{CARCOM - the "buying firm"}

The company CARCOM is the market leader in its field and offers innovative technology solutions that improve safety, the environment, and vehicle dynamics to the global vehicle industry within specific niches. Its vision is to be the global vehicle industry's first choice as a long term partner. The company is divided into three divisions, of which the division in question is the largest in terms of sales (388 million Euros) as well as number of employees (2200). CARCOM strives for long-term relations with its suppliers, which makes the selection process crucial. CARCOM states that it is important that the parties involved can benefit from the collaboration. According to the Head of the Purchasing Department, CARCOM also strives for early involvement of the suppliers. Simultaneously, the company aims to improve its internal integration, not least between the manufacturing, purchasing and the R\&D departments. In fact, several manufacturing engineers critically remarked that other departments, particularly the R\&D department, do not have enough knowledge about constrains in their production process. Consequently, $R \& D$ and manufacturing engineering represent a critical internal interface at CARCOM. However, the supplier-collaboration is an inter-organizational process.

The general process for starting a supplier-collaboration can be described as: 1) R\&D presents a draft to purchasing. 2) Purchasing sends a request for quotations to a few chosen suppliers. 3) The suppliers come back with price indications and product reviews. 4) There are meetings with the most promising suppliers. 5) The suppliers are selected. 6) The collaboration starts.

\subsection{The product development project}

Both suppliers in this study are involved in the same overall product development project. The project had been running for three years and was almost finalized when this study began. The purpose of the project was to develop a new generation of disc-brakes for heavy vehicles. Essentially, the aim was to realize the lightest disc brake on the market, with the same performance and stability as the competitors. In this way, it was expected that both the 
payload and the cost-benefit ratio profit from the product. The project was organized into several sub-projects in which different suppliers were involved.

The main challenges were to reduce weight and cost. Managerially, the selection and involvement of suppliers were specifically mentioned as two major challenges by the Head of the Purchasing Department as two major challenges. In the selection process, the aim was to find credible suppliers that could be involved early. Generally, a selection process starts by asking ten different suppliers for offers, ending up with a dual - or in specific cases - a single source. In the subsequent process of involvement, CARCOM tried to use open books, not least so that the suppliers would be aware that the large-scale production might be placed somewhere else, in countries such as China or India.

Almost all 60 components that make up the product had to be changed in the project. This fact made it necessary to start up new supplier collaborations. Out of the 29 suppliers involved, 20 were new. The collaborations chosen for this study represent two of the most important components of the disc brake - the holder and the caliper. They are quite similar in terms of complexity and manufacturing technology. However, as previously mentioned, the holder collaboration focuses on developing a completely new component, whereas the caliper collaboration focuses on improving quality and reducing cost.

The following paragraphs present the two collaborations by describing the processes of sharing and utilizing product and manufacturing knowledge in the buyer-supplier relationship and indications of the role of trust in knowledge integration.

\subsubsection{The holder collaboration}

In the holder collaboration, CARCOM used an existing supplier that was involved from the very beginning of the product development processes. This supplier specializes in casting and had been involved in CARCOM's development of a previous generation of the disk brake system. Several respondents from CARCOM, as well as from the supplier, stress that the already existing relationship and positive experiences between the buyer and the supplier played an important role and had resulted in mutual trust:

"It is a customer that is very good to work with. They have chosen to work with us in the long term." (Representative of the supplier, Holder)

It was felt that the previous relations and experiences had resulted in great improvements and a better understanding for CARCOM's and the supplier's constraints in the production system. This knowledge about each other's production systems was considered as an important favorable condition at the outset of the collaboration and the respondents expressed that this knowledge could be used during the collaboration to a great extent:

"We've actually managed to learn the lessons [from our previous collaboration]. For example, the manufacturing process has been managed better, and we have been able to reduce the number of steps in the process considerably. "(Designer at CARCOM, Holder)

Even though the supplier specializes in casting, it also has important knowledge and understanding of how to further improve the processing of the component in CARCOM's manufacturing process. The respondents stressed that to a great extent this contributed to them developing a new technological solution together as well as reducing the costs and the weight of the component:

"When it comes to casting we have the knowledge...in this case we have come up with an unusual solution together with our partner." 
"...Maybe we have succeeded in bringing knowledge from the earlier collaboration. At the same time we tried something new and became motivated. We have been able to use our previous processing knowledge on both sides." (Representative of the supplier, Holder)

Even though much of the initial communication with the supplier was channeled through the purchasing department, the respondents characterized their way of working and problemsolving as an interactive process. The communication is described as taking place in open and interpersonal dialogues, during which ideas from the supplier and the buyer were integrated:

"We have been deeply involved in this. Normally we get a drawing that we base our work on. In this case we have worked very closely with design, and together we have tried to optimize the component. The customer has been open in its calculations, so we could see the issue and critical points. There has been a very open dialogue around the development of this particular article, from the outset." (Representative of the supplier, Holder)

The collaboration continued in all phases of the product development process and focused on integrating the casting and component processing knowledge and find new solutions for the new component. The collaboration extended the R\&D-manufacturing interface to early stages of the product development process as well as to production phases. Even after releasing the product on the market, the component was further developed and optimized together with the supplier.

\subsubsection{The caliper collaboration}

In the caliper collaboration, CARCOM selected and involved a new supplier. Initially, CARCOM involved a specific supplier for the prototype. The supplier provided technical inputs for improvements. Then CARCOM selected another supplier to produce the final product. This supplier is a well-known player in the disc-brake sector, and has collaborations with several CARCOM's competitors. The respondents stressed that the selection of this supplier was based on its strong technology and production capabilities which were considered to be essential, as the component was critical and there was a considerable time pressure. Their main involvement was during one particular phase:

"This supplier was very good technically and came up with very important input to certain parts and gave suggestions for solutions." (Senior Designer at CARCOM, Caliper)

According to the respondents, the collaboration very much revolved around the exchange of technical specifications and 3D-models which were then reviewed by the supplier. This was done in order to provide feedback on the possibilities to improve the design of the component by taking into account the constraint of the casting process in the supplier's manufacturing operations:

"We make proposals in the casting area to the design department. If they can agree on them, then these optimizations come true..."

Especially in the development phase we have to react and give the feedback to our customer. So that we can change, if necessary, a tolerance or design and geometry, so this feedback is integrated later in the FMEA. "(Representative for the supplier, Caliper)

The respondents stress that the focus in the caliper collaboration was mainly to arrive at a design that provided the highest quality and that conformed to weight and cost requirements by taking into account the constraints in the manufacturing process. The supplier's casting knowledge was considered to be critical. 
"It is probably a fact that the design sets 80 percent of the price... Their (the supplier's) feedback is therefore very important and has led to geometrical changes... "' (Senior Designer at CARCOM, Caliper)

The final design also impacted the further processing of the product at CARCOM. However, the supplier did not share processing knowledge with CARCOM and the consequences of the design for CARCOM's production process were determined at CARCOM internally.

\section{Analysis}

CARCOM considers both collaborations to be successful examples of supplier involvement. From CARCOM's perspective, both suppliers contributed with valuable knowledge. The following comparative analysis focuses on differences in the knowledge integration processes related to type of trust. A summary can be found in Table I.

Table I: A summary of the comparative analysis between the two supplier collaborations

\begin{tabular}{|l|l|l|}
\hline \multicolumn{2}{|l|}{ Holder collaboration } & \multicolumn{1}{l}{ Caliper collaboration } \\
\hline Pocus in NPD & New design & Higher quality and lower cost \\
\hline Time scope of collaboration & Existing supplier & $\begin{array}{l}\text { Single phase -at the R\&D-manufacturing } \\
\text { interface }\end{array}$ \\
\hline $\begin{array}{l}\text { Supplier involvement and knowledge } \\
\text { input in the collaboration }\end{array}$ & $\begin{array}{l}\text { Preceding and following R\&D- } \\
\text { manufacturing interface }\end{array}$ & Casting \\
\hline Trust & Casting and processing & $\begin{array}{l}\text { Competence-based: } \\
\text { Competence, reputation, limiting exposure, } \\
\text { calculation }\end{array}$ \\
\hline $\begin{array}{l}\text { Characterization of knowledge } \\
\text { integration: }\end{array}$ & $\begin{array}{l}\text { Goodwill, openness, loyalty, } \\
\text { trustworthy individuals }\end{array}$ & $\begin{array}{l}\text { Knowledge is shared and utilized in a joint } \\
\text { and interactive process } \\
\text { knowledge. Buyer utilizes supplier } \\
\text { knowledge further. }\end{array}$ \\
\hline Interfaces & $\begin{array}{l}\text { Interpersonal interaction, some contacts } \\
\text { through purchasing department }\end{array}$ & $\begin{array}{l}\text { Technical interfaces, 3D design drawings, } \\
\text { purchasing department }\end{array}$ \\
\hline
\end{tabular}

The focus in the holder collaboration was on integrating the supplier's knowledge about the product and process technology in order to arrive at completely new design. The supplier was involved in all phases of the product development project. As the supplier was used in the previous disc-brake development project, a deep trust existed from the very beginning of the collaboration. In the relationship this trust seems to be founded on shared norms, trustworthy individuals, and goodwill (cf. Blomqvist, 1997; Sengün, 2010). It is represented in openness and direct interpersonal contact (cf. Adler, 2001). As a consequence of the previous collaboration - and the trust it had created - the holder supplier was deeply integrated in the project and was able to contribute with its knowledge through a joint and interactive process. The sharing, utilization, and extension of knowledge and took place in a coupled process. This interactive process, resulted in a new, lighter component that could be produced at lower costs. This process is quite similar to how Nonaka (1994), Nonaka and Takeuchi (1995), and Alawi and Tiwana (2002) describe knowledge integration, although in an intra-organizational context. The dominant knowledge integration mechanism seems to be integrated group problem-solving as formulated by Grant (1996). The focus is on on-going joint knowledge integration where both partners have the possibility to learn from each other (cf. Okhuysen and Eisenhardt, 2002).

In the caliper collaboration, the focus was to improve quality and decrease cost by using the supplier's manufacturing knowledge. The supplier was involved for a limited time period. A different dimension of trust was emphasized in this collaboration; the supplier was mainly selected because of its reputation and competence (cf. Blomqvist, 1997; Sengün, 2010). A 
calculative form of trust is present, as it is essentially based on a calculation of costs and benefits (cf. Adler, 2001). Technical interfaces were used for the exchange of 3D-models, rather than interpersonal interfaces. The focus seems to be on the efficiency of knowledge integration in line with the ideas of Grant (1996) as well as Schmickl and Kieser (2008). In addition, the supplier was considered as less dependent and less interested in the relationship with CARCOM. Consequently, CARCOM was inclined to limit its exposure to the supplier. Therefore, knowledge integration was built on an intention to capture manufacturing knowledge from the supplier by asking the supplier to share its knowledge with CARCOM. This knowledge was further integrated mainly by the CARCOM itself. Consequently, although knowledge sharing occurred at the interface between the buyer and the supplier, the buyer itself used supplier knowledge further for combining, extending and possibly recombining knowledge used in the overall product design. Consequently, in the caliper collaboration, knowledge sharing was decoupled from utilization. No joint buyer-supplier knowledge was created.

The two different knowledge integration processes, based on joint, interactive learning, and capturing supplier knowledge, in combination with different types of trust identified, are illustrated in figure 1.

RELATIONAL-BASED TRUST

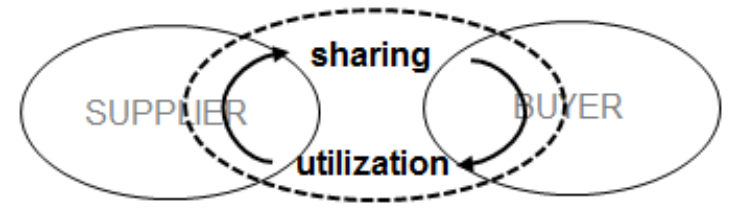

JOINT LEARNING
COMPETENCE-BASED TRUST

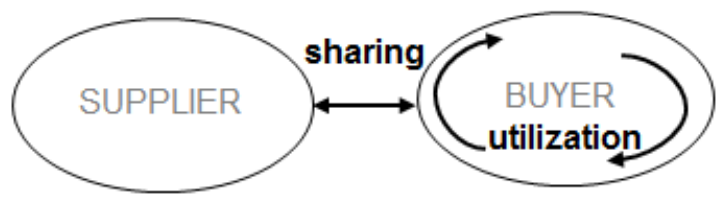

CAPTURING

Figure 1: Two knowledge integration approaches and their different types of trust

Joint and interactive learning represents a coupled form of knowledge integration, where sharing and utilization take place interactively and recurrently over a longer period of time, extending the R\&D-manufacturing interface in time. In contrast, capturing takes place by decoupling sharing, which occurs during a limited time period, demarcating the R\&Dmanufacturing interface, and by utilization, which takes place mainly at the buyer. It seems that coupled integration is based on high degrees of relational-based trust, while decoupled integration instead builds on a high degree of confidence in the competence of the supplier.

\section{Conclusion}

This paper has investigated how supplier knowledge is integrated in product development collaborations. The underlying research questions were: What characterizes the knowledge integration processes in buyer-supplier collaborations in product development? What is the role of trust in these processes?

The paper shows that trust is important for knowledge integration in terms of sharing and utilizing knowledge. However, it seems that firms in inter-organizational collaborations do not necessarily strive for, "the more trust the better". In fact, by studying collaborations that 
focus on product technology and process technology, the findings provide indications that different types of trust enable different knowledge integration processes. In firms where suppliers manufacture part of the product, this has important consequences for the R\&Dmanufacturing interface. Thus, this paper has shown that buyer-supplier collaborations extend the R\&D-manufacturing interface to include not only intra-organizational but interorganizational aspects as well.

The results show that knowledge integration approaches and types of trust vary in different situations. Knowledge integration can take place when buyers and suppliers have confidence in each other's competence and reputation. When buyers and suppliers perceive that the benefits of the knowledge input of the suppliers outweigh the cost of the negative consequences of potential knowledge leakages, limited interaction, mainly through technical interfaces, may be established. This is in line with the focus on efficiency in the work by Grant (1996) on the knowledge based view of the firm. The integration of the external supplier knowledge is perceived as key to product development success, but this does not always need to imply joint and interactive knowledge integration approaches, as has been suggested (e.g. Okhuysen and Eisenhardt, 2002; Tiwana and McLean, 2005; Huang and Newell, 2003). Rather, important supplier knowledge is captured in a collaborative relationship and successively utilized by the buyer.

Further, the paper shows that there are instances when high degrees of trust are important, especially for more exploratory tasks that are executed by joint and interactive processes of knowledge integration. These joint and interactive processes couple sharing and the utilization of knowledge. When trust is profound and based on relationships, conditions are created for knowledge integration through joint sharing and utilization across organizational boundaries. Such joint processes have been exemplified in intra-organizational settings in previous research by Okhuysen and Eisenhardt (2002), and it is shown that these processes also occur across organizational borders at the R\&D-manufacturing interface.

Our findings support Das and Teng's (2001) and Lui and Ngo's (2004) work and elaborate on their findings that it is crucial to identify specific relationships among different trust types and organizational outcomes. Specifically, the paper contributes to the relationship between trust and knowledge integration processes by showing that different types of trust promote coupled or decoupled knowledge integration processes. The study relates relational trust to coupled knowledge integration, i.e., sharing and utilization through extended joint interactive learning. Competence-based trust is related to decoupled knowledge integration, i.e., capturing supplier knowledge through sharing while subsequently utilization occurs mainly in isolation of the supplier. On a broader perspective, the study bridges the gap between innovation and operations management, as managing byer-supplier collaborations interfaces not only R\&D and manufacturing, but also with traditional corporate boundaries in the pursuit of collaborative innovation.

The study's implications for the management of the interface between R\&D and manufacturing can be formulated in two main points. Firstly, management needs to consider the intra-organizational as well as the inter-organizational aspects of this interface as the interface involves knowledge integration between internal manufacturing and the R\&D function as well as inter-organizational relationships with suppliers. Knowledge has to cross several functional boundaries and 'thought worlds' before a new product is in place. Secondly, the inter-organizational relationships with suppliers need to be carefully designed according to relationship conditions in terms of trust, product development task, task of the supplier, and knowledge integration mechanisms. Careful choices need to be made between joint and interactive processes and more distant capturing and accessing processes. In the first 
case, where joint learning is central to provide new solutions, there is a serious risk of losing important knowledge. Here, except for creating and maintaining relational trust, managers need to find a collaborative mechanism that maximizes the inflow of skills and minimizes outflow. Management needs to locate the interface points, staff and train appropriately, develop sound reward systems and monitor the exchange of information (cf. Baughn et al., 1997). In the second knowledge capturing case of exposure to the supplier, and consequently the risks for unforeseen knowledge spill-over, is more limited, but so are the possibilities of arriving jointly at new solutions.

\section{Limitations and future research}

As the findings are based on a dual case study, additional cases in different companies and industries are needed for improving the theoretical insights gained from this study (Yin, 2009). Further research may also be needed to test the generalizability; i.e., actual replication of the findings. Future research can also help to identify the impacts of inter-organizational contextual variables, such as power and dependence across trading partners. Likewise, the architecture and rate of technological development or innovation for the product in question may affect the knowledge integration efforts. For example, according to Squire et al. (2009), product modularization may decrease the knowledge transfer required as interfaces can be fully specified to suppliers. The differences between transfer of tacit versus explicit knowledge via trust (cf. Becerra et al., 2008) would be another fruitful avenue for further elaboration of the contributions of this paper.

\section{Acknowledgements}

We are very grateful for the access provided by CARCOM to gather data about their product development project and collaborations with suppliers. This study forms part of the research project KIC - Knowledge Integration and Collaboration with Suppliers - which is funded by the Swedish Agency for Innovation Systems (VINNOVA) and Ragnar Söderberg Foundation, whom we would like to thank.

\section{References}

Adler, P. S. (2001), "Market, hierarchy, and trust: The knowledge economy and the future of capitalism", Organization Science, Vol.12 No.2, pp. 215-234.

Adler, P. S. and Kwon, S. W. (2002), "Social capital: Prospects for a new concept", Academy of Management Review, Vol. 27, pp. 17-40.

Alawi, M. and Tiwana, A. (2002), "Knowledge integration in Virtual Teams: The potential rof KMS", Journal of the American Society for Information and Science and Technology, Vol. 53 No. 12, pp. 1029-1037.

Alvesson, M. (2011), Intervjuer - genomförande, tolkning och reflexivitet, Liber, Malmö.

Appleyard, M. M. (2003), "The influence of knowledge accumulation on buyer-supplier codevelopment projects", Journal of Product Innovation Management, Vol. 20 No. 5, pp. 356-373.

Baughn, C. C., Stevens, J. H., Denekamp, J. G, and Osborn, R. N. (1997), "Protecting intellectual capital in international alliances", Journal of World Business, Vol. 32 No. 2, pp. 103-117.

Becerra, M., Lunnan, R., and Huemer, L. (2008), "Trustworthiness, risk, and the transfer of tacit and explicit knowledge between alliance partners", Journal of Management, Vol. 45, pp. 693-713.

Beecham, M.A. and Cordey-Hayes, M. (1998), "Partnering and knowledge transfer in the UK motor industry", Technovation, Vol. 18 No.3, pp. 191-205.

Becker, M. and Zirpoli, F. (2003), "Organizing new product development: Knowledge hollowing - out and knowledge integration - the FIAT Auto case". International Journal of Operation \& Production Management, Vol. 23 No. 9, pp. 1033-1061 
.Bhandar, M., Pan, S-L, and Tan, B. C.Y. (2006), "Towards understanding the roles of social capital inknowledge integration: A case study of a collaborative information systems project", Journal of the American Society for Information Science and Technology, Vol. 58 No. 2, pp. 263-274.

Blomqvist, K. (1997), “The many faces of trust”, Scandinavian Journal of Management, Vol. 13 No. 3, pp. 271286.

Brown, D. P. and Eisenhardt, K. M. (1995), Product Development: Past Research, Present Findings, and Future Directions, Vol. 20 No. 3, pp. 343-378.

Bryman, A. (2008), Social Research Methods, Oxford University Press, New York.

Carlile, P. R. (2002), "A pragmatic view of knowledge and boundaries: boundary objects in new product development", Organization Science, Vol. 13 No. 4, pp. 442-455.

Clark, K. B. (1989),"Project scope and project performance - The effect of parts strategy and supplier involvement on product development", Management Science, Vol. 35 No. 10, pp. 1247-1263.

Cousins, P. D., Lawson, B., Petersen, K. J., Handfield, R. B. (2011), "Breakthrough scanning, supplier knowledge exchange, and new product development performance", Journal of Product Innovation Management, Vol. 28, pp. 930-942.

Creswell, J.W. (2009), Research Design, Sage, Thousand Oaks, CA.

Das, T. K. and Teng, B. S. (2001), "Trust, control and risk in strategic alliances: An integrated framework", Organization Studies, Vol. 22, pp. 251-283.

Dyer, J. H., and Chu, W. (2003), "The role of trustworthiness in reducing transaction costs and improving performance: Empirical evidence from the United States, Japan, and Korea", Organization Science, Vol. 14 No. 1, pp. 57-68.

Dyer, J. H. and Nobeoka, K. (2000), "Creating and managing a high-performance knowledge-sharing network: The Toyota case", Strategic Management Journal, Vol. 21, pp. 345-367.

Dyer, J. H., and Singh, H. (1998), "The relational view: Cooperative strategy and sources of interorganizational competitive advantage", Academy of Management Review, Vol. 23, No. 4, pp. 660-679.

Eisenhardt, K. M. (1989), "Building theories from case study research", Academy of Management Review, Vol. 14 No. 4, pp. 235-250.

Eisenhardt, K. M., and Graebner, M. E. (2007), "Theory building from cases: Opportunities and challenges". Academy of Management Journal, Vol. 50 No. 1, pp. 25-32.

Fawcett, S. E., Jones, S. L., and Fawcett, A. M. (2012), "Supply chain trust: The catalyst for collaborative innovation", Business Horizons, Vol. 55, pp.163-178.

Firestone, W. A. (1993), "Alternative arguments for generalizing from data as applied to qualitative research". Educational researcher, Vol. 22 No. 4, p. 16

Gambetta, D., ed. (1988), Trust: Making and Breaking Cooperative Relations, Basil Blackwell, Oxford, U.K.

Grandori, A. (2001), "Neither hierarchy nor identity: Knowledge-governance mechanisms and the theory of the firm", Journal of Management and Governance, Vol. 5, pp. 381-399.

Grant, R. M., (1996), "Prospering in dynamically-competitive environments: Organizational capability as knowledge integration", Organization Science, Vol. 7 No. 4, pp. 375-387.

Grant, R. M. (2002), "The knowledge-based view of the firm", In C. W. Choo and N. Bontis (Eds.), The Strategic Management of Intellectual Capital and Organizational Knowledge, pp. 133-148. Oxford, Oxford University Press.

Grant, R. M. and Baden-Fuller, C. (2004), "A knowledge accessing theory of strategic alliances", Journal of Management Studies, Vol. 41 No. 1, pp. 61-84.

Ha, B-C., Park, Y-K., and Cho, S. (2010), "Suppliers' affective trust and trust in competency in buyers: Its effect on collaboration and logistics efficiency", International Journal of Operations and Production Management, Vol. 31 No. 1, pp. 56-77.

Hammervoll, T. (2012), "Managing interaction for learning and value creation in exchange relationships", Journal of Business Research, Vol. 65, pp. 128-136.

Hansen, M. T. (1999), "The search transfer problem: the role of weak ties in sharing knowledge across organizational subunits", Administrative Science Quarterly, Vol. 44, pp. 82-111.

Heiman, B., A., and Nickerson, J. A. (2004), "Empirical evidence regarding the tension between knowledge sharing and knowledge exproproation", Strategic Management Journal, Vol. 25, No. 8-9, pp. 723-749.

Heiman, B., A., and Nickerson, J. A. (2002), "Towards reconciling transaction cost economics and the knowledge-based view of the firm: The context of interfirm collaborations", International Journal of Economics of Business", Vol. 9 No.1, pp. 97-116.

Henderson, R. M., and Clark, K. B. (1990), "Architectural innovation - the reconfiguration of existing product technologies and the failure of established firms", Administrative Science Quarterly, Vol. 35 No. 1, pp. 930.

Hong, P., Doll, W. J., Nahm, A. Y., Li, X. (2004), "Knowledge sharing in integrated product development", European Journal of Innovation Management, Vol. 7, pp. 102-112. 
Huang, J., and Newell, S. (2003), "Knowledge integration processes and dynamics within the context of crossfunctional projects", International Journal of Project Management, Vol. 21, pp. 167-176.

Inkpen, A. C. and Tsang, E. W. K. (2005), "Social capital, networks and knowledge transfer", Academy of Management Review, Vol. 30, pp. 146-165.

KPMG (2012), Global Manufacturing Outlook: Fostering Growth through Innovation, KPMG International, Geneva.

Koufteros, X., Vonderembse, M., and Jayaram, J. (2005), "Internal and external integration for product development: The contingency effect of uncertainty, equivocality, and platform strategy", Decision Sciences, Vol. 36 No 1, pp. 97-133.

Kogut, B., and Zander, U. (1992), "Knowledge of the firm, combinative capabilities, and the replication of technology". Organization Science, Vol. 3, No. 3, pp. 383-397.

LaBahn, D. W., and Krapfel, R. (2000), "Early supplier involvement in customer new product development: A contingency model of component supplier intentions", Journal of Business Research, Vol. 47 No. 3, pp. 173-190.

Lau, A. K. W., Tang, E. and Yam, R. C. M. (2010), "Effects of supplier and customer integration on product innovation and performance: Empirical evidence in Hong Kong manufacturers", Journal of Product Innovation Management, Vol. 27 No. 5, pp. 761-77.

Liker, J..K., Kamath, R. R., Wasti, S. N., and Nagamachi, M. (1996), "Supplier involvement in automotive component design: are there really large US and Japanese differences? Research Policy, Vol. 25, pp. 273290.

Lincoln, J. R., Ahmadjian, C. L., and Mason, E. (1998), "Organizational learning and purchase-supply relations in Japan: Hitachi, Matsushita, and Toyota compared", California Management Review, Vol. 40 No. 3, pp. 241-255.

Lui, S. S. and Ngo, H. (2004), "The role of trust and contractual safeguards on cooperation in non-equity alliances", Journal of Management, Vol. 30, pp. 471-485.

Luo, Y. (2006), "Opportunism in inter-firm exchanges in emerging markets", Management and Organization Review, Vol. 2, pp. 121-147.

March, J. G. (1991), "Exploration and Exploitation in Organizational Learning". Organization Science, Vol. 2 No. 1, pp. 71-88.

Miles, M., B., Huberman, A. M. (1994), Qualitative Data Analysis: An Expanded Sourcebook, Sage Publications, Thousand Oaks, California.

Nahapiet, J. and Ghoshal, S. (1998), "Social capital, intellectual capital, and the organizational advantage", Academy of Management Review, Vol. 23, pp. 242-266.

Nobelius, D. (2004), "Linking product development to applied research: Transfer experiences from an automotive company", Technovation, Vol. 24, No. 4, pp. 321-334.

Nonaka, I. (1994), "A dynamic theory of organizational knowledge creation", Organizational Science, Vol. 5 No. 1, pp. 14-37.

Nonaka, I., and Takeuchi, H. (1995), The Knowledge Creating Company: How Japanese Companies Create the Dynamics of Innovation, Oxford University Press, Oxford.

Nooteboom, B. (2003), "The trust process", in: B. Nooteboom and F. Six (Eds,), The Trust Process in Organizations, Edward Elgar, Cheltenham, pp. 16-36.

Okhuysen, G. A. and Eisenhardt K. M. (2002), "Integrating knowledge in groups: How formal interventions enable flexibility", Organization Science, Vol. 13 No. 4, pp. 370-386.

Polanyi, M. (1966), The Tacit Dimension, Routledge and Kegan Paul, London.

Ragatz, G. L., Handfield, R. B., and Petersen, K. J. (2002), "Benefits associated with supplier integration into new product development under conditions of technology uncertainty", Journal of Business Research, Vol. 55 No 5, pp. 389-400.

Ragatz, G. L., Handfield, R. B., and Scannell, T. V. (1997), "Success factors for integrating suppliers into new product development", Journal of Product Innovation Management, Vol. 14 No. 3, pp. 190-202.

Ring, P., S., and Van de Ven, A., H. (1992), "Structuring cooperative relationships between organizations", Strategic Management Journal, Vol. 13, pp. 483-498.

Rosell, D. T, and Lakemond, N. (2012), "Collaborative innovation with suppliers - a conceptual model for characterising supplier contributions to NPD ", International Journal of Technology Intelligence and Planning, Vol. 8 No. 2, pp. 197-214.

Sako, M. (1992), Prices, Quality and Trust: Inter-firm Relations in Britain and Japan, Cambridge University Press, Cambridge.

Sako, M., and Helper, S. (1998), "Determinants of trust in supplier relations: Evidence from the automotive industry in Japan and the United States", Journal of Economic Behavior and Organization, Vol. 34 No. 3 , pp. 387-417. 
Schmickl, K. and Kieser, A. (2008), "How much do specialists have to learn from each other when they jointly develop radical product innovations? ", Research Policy, Vol. 37 No. 3, pp. 473-491.

Selnes, F., and Sallis, J. (2003), "Promoting relationship learning", Journal of Marketing, Vol. 67, pp. 80-95.

Sengün, A. E. (2010), "Which type of trust for inter-firm learning?", Industry and Innovation, Vol. 17, pp. 193213.

Smitka, M. J. (1991), "The invisible handshake - the development of the Japanese automobile parts industry", Business and Economics History Series, Vol. 19 No. 2, pp. 153-171.

Squire, B., Cousins, P. D., and Brown, S. (2009), "Cooperation and knowledge transfer within buyer-supplier relationships: The moderating properties of trust, relationship duration and supplier performance", British Journal of Management, Vol. 20, pp. 461-477.

Tatikonda, M., V., and Stock, G., N. (2003), "Product technology transfer in the upstream supply chain", Journal of Product Innovation Management, Vol. 20 No. 6, pp. 444-467.

Tiwana, A., and McLean, E. (2005), "Expertise integration and creativity in information systems development", Journal of Management Information Systems, Vol. 22 No. 1, pp. 13-43.

Tsai, W. S. and Ghoshal, S. (1998), "Social capital and value creation: the role of inter-firm networks", Academy of Management Journal, Vol. 41, pp. 464-476.

Van de Ven, A. H., Delbecq, A. L., and Koenig Jr., R. (1976), "Determinants of coordination modes within Organizations", American Sociological Review, Vol. 41 No. 2, pp. 322-338.

Walter, A. (2003), "Relationship-specific factors influencing supplier involvement in customer new product development", Journal of Business Research, Vol. 56 No. 9, pp. 721-733.

Yin, R. (2009), Case study Research: Design and Methods, Third ed., Sage, Beverly Hills, CA.

\section{About the authors}

David T Rosell is a PhD Candidate at the Department of Management and Engineering, Linköping University, Sweden. His main research interests concern innovation management, project management, and inter-organizational collaborations. He is the corresponding author and can be contacted at: david.rosell@liu.se

Nicolette Lakemond is an Associate Professor at the Department of Management and Engineering, Linköping University, Sweden, and member of the KITE Research Group (www.liu.se/kite). Her research interests are in the field of management of product development and innovation. She is specifically interested in collaborative innovation with suppliers, knowledge integration in innovation, integrated solutions and creativity.

S. Nazli Wasti is a Professor of Business Administration at Middle East Technical University, Turkey. Her research interests include buyer-supplier relations, interorganizational trust, and innovation management. 